\title{
Ice Roughness and Thickness Evolution on a Swept NACA 0012 Airfoil
}

\author{
Stephen T. McClain ${ }^{1}$ \\ Baylor University, Waco, TX 76798-7356 \\ Mario Vargas ${ }^{2}$ \\ NASA Glenn Research Center, Cleveland, OH 44135 \\ and \\ Jen-Ching $\mathrm{Tsao}^{3}$ \\ Ohio Aerospace Institute, Cleveland, $\mathrm{OH} 44142$
}

\begin{abstract}
Several recent studies have been performed in the Icing Research Tunnel (IRT) at NASA Glenn Research Center focusing on the evolution, spatial variations, and proper scaling of ice roughness on airfoils without sweep exposed to icing conditions employed in classical roughness studies. For this study, experiments were performed in the IRT to investigate the ice roughness and thickness evolution on a 91.44-cm (36-in.) chord NACA 0012 airfoil, swept at 30-deg with $0^{\circ}$ angle of attack, and exposed to both Appendix $\mathrm{C}$ and Appendix $\mathrm{O}$ (SLD) icing conditions. The ice accretion event times used in the study were less than the time required to form substantially three-dimensional structures, such as scallops, on the airfoil surface. Following each ice accretion event, the iced airfoils were scanned using a ROMER Absolute Arm laser-scanning system. The resulting point clouds were then analyzed using the self-organizing map approach of McClain and Kreeger to determine the spatial roughness variations along the surfaces of the iced airfoils. The resulting measurements demonstrate linearly increasing roughness and thickness parameters with ice accretion time. Further, when compared to dimensionless or scaled results from unswept airfoil investigations, the results of this investigation indicate that the mechanisms for early stage roughness and thickness formation on swept wings are similar to those for unswept wings.
\end{abstract}

\section{Nomenclature}

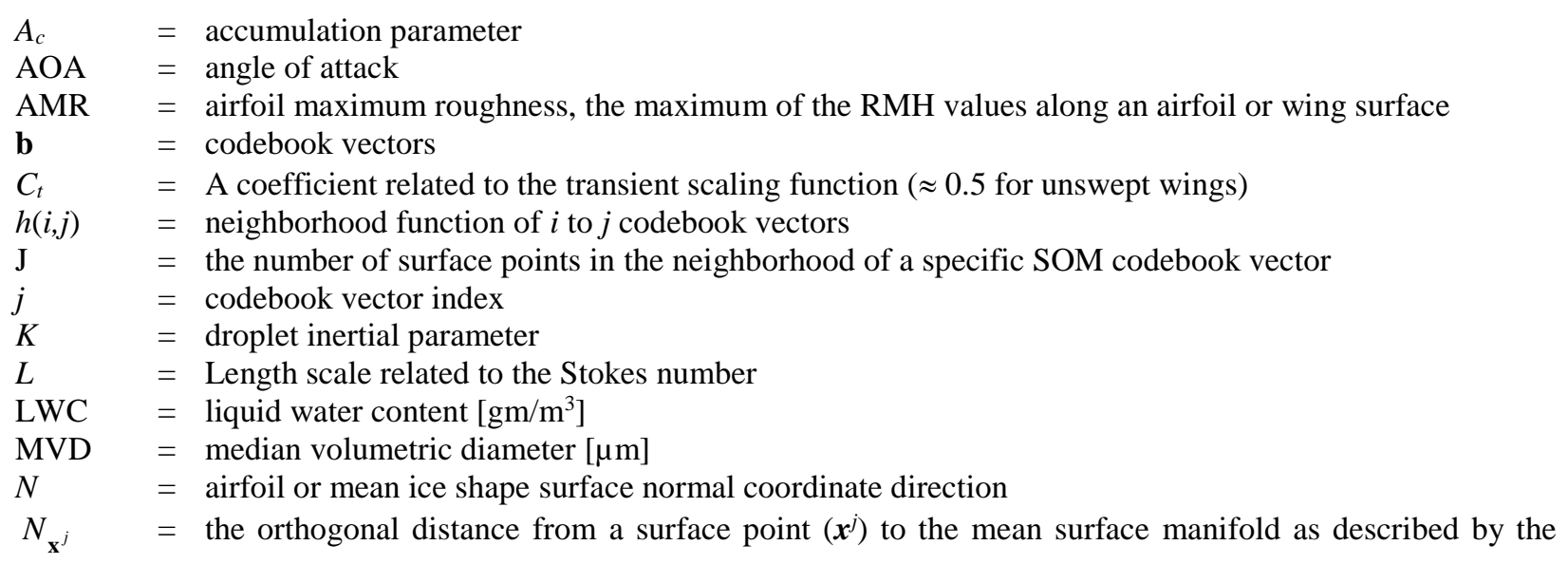

\footnotetext{
${ }^{1}$ Associate Professor, Department of Mechanical Engineering, One Bear Place \#97356, AIAA Senior Member.

${ }^{2}$ Aerospace Engineer, Icing Branch, 21000 Brookpark Rd., MS 11-2, AIAA Associate Fellow.

${ }^{3}$ Principal Research Scientist, Icing Branch, 21000 Brookpark Rd., MS 11-2, AIAA Associate Fellow.
} 
SOM codebook vectors

$N_{0, R} \quad=$ Fully-dense Rime ice stagnation thickness on unswept wings

$N_{\Lambda, R} \quad=$ Fully-dense Rime ice surface-orthogonal thickness on swept wings

$\bar{N}_{0} \quad=$ the measured ice orthogonal-thickness at each codebook vector relative to the clean wing surface

$\bar{N}_{0, A L} \quad=$ the measured attachment line orthogonal-thickness relative to the clean airfoil or wing surface

$n=$ stagnation point freezing fraction

$R M H=99 \%$-Gaussian roughness maximum height evaluated at each codebook vector $\left(=3.09 R_{q}\right)$

$R_{q} \quad=$ the root-mean-square or "standard deviation" roughness height

$r_{a} \quad=$ leading edge radius of curvature

SOM $=$ Self-Organizing Map

$S \quad=$ mean ice shape surface tangential coordinate direction

$S_{0} \quad=$ the clean airfoil tangential coordinate direction and distance

$\varsigma(\sigma) \quad=$ Spatial scaling function

$\mathrm{Sk}=$ Stokes number

$\mathfrak{J}(\tau) \quad=$ Transient (time-based) scaling function

$T_{\text {static }}=$ the freestream static temperature

$T_{\text {total }}=$ the freestream stagnation or total temperature

$\operatorname{Vor} U_{\infty}=$ Freestream velocity

$\mathbf{x}=$ element of point cloud data set

$x \quad=$ a random variable

$\alpha=$ local direction angle of manifold through a codebook vector or airfoil angle of attack

$\beta_{f b} \quad=$ local surface collection efficiency at the location of the liquid-film breakdown

$\beta_{s} \quad=$ local surface collection efficiency

$\beta_{0} \quad=$ straight wing stagnation collection efficiency

$\beta_{\Lambda} \quad=$ swept wing attachment-line collection efficiency

$\gamma=$ direction angle of surface point relative to manifold direction through winning codebook vector

$\gamma_{s} \quad=$ direction angle of a surface point relative to the airfoil design coordinates

$\gamma_{f b}=$ direction angle of the surface point of liquid-film break down relative to the airfoil design coordinates

$\Delta t_{s} \quad=$ the ice accretion event time

$\Lambda \quad=$ Sweep angle

$\rho_{\text {ice }} \quad=$ density of ice

$\rho_{w} \quad=$ density of liquid water

$\sigma \quad=$ Scaled position parameter

$\tau \quad=$ Scaled time parameter

$\mu_{\text {air }}=$ viscosity of air

\section{Introduction}

$\mathrm{R}$ OUGHNESS on iced airfoils increases the skin friction drag, increases the rates of heat transfer from the freezing water layer to the airstream, and induces higher levels of boundary-layer turbulence than would be observed on mean representative ice shapes without roughness. Further, ice roughness increases the droplet capture efficiency of the local surface relative to a smooth surface. Because it couples the fluid flow, heat transfer, and droplet impingement processes, ice roughness formed during the early stages of the ice accretion process is an important factor in the overall in-flight ice accretion process and is thought to ultimately affect the resulting ice shapes exhibited much later in the ice accretion process.

Because of its importance to the overall ice accretion process, the study of roughness on ice accretion surfaces has a long history. However, most of the historical studies have involved image analysis approaches to characterize roughness element morphology. References [1-3] represent examples of the morphological roughness investigations. Following the development of laser scanning techniques in the Icing Research Tunnel (IRT) at NASA Glenn Research Center [4-7], several investigations of ice roughness evolution [8,9] and ice roughness scaling [10] have been performed on straight wings with symmetric (NACA 0012) airfoil shapes. More specifically, the roughness evolution investigations of McClain et al. [8] and McClain et al. [9] focused on the temporal evolution of roughness, while the scaling investigation of McClain et al. [8] focused on the spatial variations of roughness features by identifying the proper scaling quantities relative to the stagnation point cloud collection efficiency. 
While the previous laser-scanning studies have provided significant insights into roughness temporal and spatial evolution on straight wings, roughness evolution on swept wings have yet to be addressed. Vargas [11] presented review of swept-wing roughness mechanisms. Vargas [11] indicated a need to better understand swept-wing roughness evolution and morphology because of their importance on scallop and lobster-tail formation on swept wings. Because the boundary-layers on swept wings are three-dimensional, the morphology of the roughness elements are thought to be critical to promoting instabilities in the boundary-layers and leading to the formation of the highly three-dimensional ice features formed and observed on swept wings.

The objectives of this study were to measure ice roughness and thickness topographies on swept wings during short-time icing events, that is, before the formation of large three-dimensional features such as scallops or lobstertails. For the study, the same basic Appendix C [12] and SLD [13] conditions of McClain et al. [9] and McClain et al. [8], which were based on the classical investigation of Anderson et al. [3], were employed. The temporal evolution and the scaled spatial evolution results will be compared to the past studies on straight wings to investigate similarities between straight and swept-wing roughness evolution. By illuminating the physics of swept-wing roughness evolution, the effort seeks to improve the heat transfer model in NASA ice accretion codes, LEWICE 2D and LEWICE 3D, which will be used in the design of current and future air vehicles employing swept wings or blended surfaces.

\section{Roughness Scaling Concepts}

The prior straight-wing roughness and evolution studies [8-10] have approached the issue of roughness temporal evolution and spatial variations as separable aspects of the roughness formation process. That is, the temporal evolution and the spatial variations along the airfoil surface are modeled using the product of a scaled time function and spatial function.

$$
R M H\left(t, S_{0}, L W C, M V D \ldots\right)=\mathscr{J}(\tau) \mathfrak{\delta}(\sigma)
$$

In Eq. (1), $\mathscr{J}(\tau)$ is a function that depends on the icing event time and the supercooled cloud properties related to the impingement process, and $\delta(\sigma)$ is function that relates to the surface position, that is its geometry relative to the upstream flow, and to the supercooled cloud properties related to the liquid film dynamics.

The temporal function relates to the exposure time of the aircraft surface in a supercooled cloud. For traditional aerosol-and-air problems, the Stokes number is defined as

$$
S k=\frac{\rho_{w} U_{\infty} M V D^{2}}{18 \mu_{\text {air }} L}
$$

Following the development of Tsao and Lee [14] and Tsao and Kreeger [15], when the length scale employed in the Stokes number definition is the leading edge radius of the airfoil, the result is commonly referred to in the icing literature as the droplet inertial parameter, $K$ :

$$
K=\frac{\rho_{w} U_{\infty} M V D^{2}}{18 \mu_{\text {air }} r_{a}}
$$

To maintain droplet trajectory similarity, the Langmuir and Blodgett [16] stagnation point collection efficiency, $\beta_{0}$, is employed where

$$
\beta_{0}=\frac{1.4\left(K_{0}-\frac{1}{8}\right)}{1+1.4\left(K_{0}-\frac{1}{8}\right)}
$$

In Eq. (4), $K_{0}$ is the modified inertial parameter of Langmuir and Blodgett [16], defined as 


$$
K_{0}=\frac{1}{8}+\frac{\lambda}{\lambda_{S k}}\left(K-\frac{1}{8}\right)
$$

where the parameter $\lambda / \lambda_{S k}$ is the droplet range parameter and is defined as a function of the droplet Reynolds number, $\operatorname{Re}_{\delta}=\rho V M V D / \mu$, as

$$
\frac{\lambda}{\lambda_{S k}}=\frac{1}{0.8388+0.001483 \mathrm{Re}_{\delta}+0.01847 \sqrt{\mathrm{Re}_{\delta}}}
$$

Once the stagnation point collection efficiency is known, the volume of ice impinging an incremental area, as depicted in Figure 1, may be evaluated as

$$
d \forall_{i c e}=\frac{L W C \cdot V \cdot \beta_{0} \cdot \Delta t_{s}}{\rho_{\text {ice }}} d A
$$

Dividing by the incremental area and multiplying by $2 r_{0} / 2 r_{0}$ results in what McClain et al. [10] referred to as the leading-edge, fully-dense, theoretical rime ice $(n=1)$ thickness, $N_{0, R}$, for straight wings and airfoils.

$$
N_{0, R}=\frac{L W C \cdot V \cdot \beta_{0} \cdot \Delta t_{s}}{\rho_{\text {ice }}} \frac{2 r_{0}}{2 r_{0}}=2 r_{0} A_{c} \beta_{0}
$$

In Eq. (8), $A_{c}$ is the accumulation parameter defined as

$$
A_{c}=\frac{L W C \cdot V \cdot \Delta t_{s}}{2 r_{0} \cdot \rho_{i c e}}
$$

For straight wings, the prior laser-scan based scaling investigation [10] expressed the temporal function in terms of the $99 \%$ maximum roughness height was found to be approximately

$$
\mathscr{J}(\tau)=A M R\left(\Delta t_{s}, \text { cloud properties }\right)=C_{t} N_{0, R}
$$

Revisiting McClain et al. [10], the constant $C_{t}$ for unswept wings was found to be approximately 0.5 , and captured both the roughness evolution versus time and the stagnation point ice thickness versus time.

For swept wings with surfaces oblique to the flow, $d A$ in Figure 1 is the projected area in the direction of the flow, and the Rime ice would be expected to spread over the actual surface area. Consequently, the fully-dense, theoretical Rime ice thickness definition of Eq. (8) would be modified as shown in Eq. (11) to represent the swept wing leading-edge "surface-orthogonal" Rime ice thickness, $N_{\Lambda, R}$.

$$
N_{\Lambda, R}=2 r_{0} A_{c} \beta_{0} \cos (\Lambda)
$$

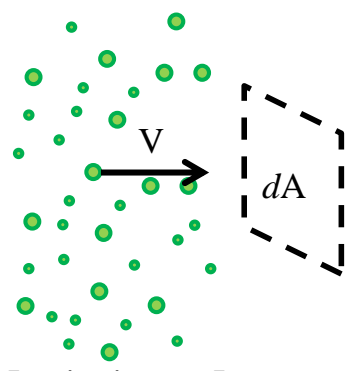

Figure 1. Supercooled Cloud Impinging an Incremental Area on a Stagnation Line 
For straight wings, McClain et al. [10] found that surface roughness variations along the ice surface were separated into two regions, as demonstrated in Figure 2(a), and defined based on the local collection efficiency corrected by the local surface angle relative to the flow. In the first region, the roughness features were suspected as being formed by the liquid film instability dynamics, while in the second region, collection efficiency dynamics governed the roughness variations. While an expression was not provided by McClain et al. [10], near and aft of the glaze ice plateau where the surface collection physics are dominant, the surface variations are reasonably well described using Eq. (12), which is represented by the gray, dashed curve in Figure 2(a).

$$
\delta(\sigma)=\frac{R M H\left(\beta_{s}, \beta_{f b}\right)}{C_{t} N_{0, R}}=\frac{W e i\left(\beta_{s}-0.05, \beta_{f b}-0.15,3\right)}{W e i\left(0.875\left(\beta_{f b}-0.15\right), \beta_{f b}-0.15,3\right)}+\left(\frac{0.1}{2}-\frac{0.1}{2} \tanh \left[10\left(\beta_{f b}-\beta_{s}\right)\right]\right)
$$

Where

$$
\begin{gathered}
\beta_{s}=\beta_{0} \cos \left(\gamma_{s}+\alpha\right) \\
\beta_{f b}=\beta_{0} \cos \left(\gamma_{f b}+\alpha\right)
\end{gathered}
$$

and $\gamma_{s}$ is the angle of the surface relative to the airfoil design flow coordinates, as depicted in Figure 3, $\alpha$ is the angle of attack, and $\gamma_{f b}$ is surface angle relative to the airfoil design coordinates at the location of the liquid-film break down and ultimately the location of the glaze ice plateau. Further, Wei $(x, \lambda, k)$ in Eq. (12) is the Weibull probability density function described as

$$
W e i(x, \lambda, k)=\frac{k}{\lambda}\left(\frac{x}{\lambda}\right)^{k-1} e^{-(x / \lambda)^{k}}
$$

Where $x$ is a positive real number, $\lambda$ is referred to as the scale parameter, and $k$ is called the shape parameter or often referred to as the Weibull modulus.

In equation (12), $C_{t}$ is set to 0.5 , and the local collection efficiency at the point of film breakdown $\left(\beta_{f b}\right)$ was set to 0.45. These values are represented in Figure 2 by the black dashed lines. In both Figure 2(a), which presents the scaled roughness heights for the unswept wing results, and Figure 2(b), which presents the scaled ice thickness measurements for the unswept wing results of McClain et al. [10], the horizontal dashed lines represent a $C_{t}$ value of 0.5 based on the ordinate variable definition and an ordinate value of 1.0. The collection efficiency at the point of film breakdown $\left(\beta_{f b}\right)$ is identified in both Figure $2(\mathrm{a})$ and $2(\mathrm{~b})$ by the vertical dashed line in each subfigure. In Figure 2(b), the location of $\beta_{f b}$ is more easily identified as the location where the thickness measurements transition from the stagnation region to the collection efficiency region, which was also identified by McClain et al. [10] as the edge of the glaze-ice plateau.

For swept wings, roughness in regions where the collection efficiency physics are dominant would be expected to follow a variation similar to Eq. (12). However, the local collection efficiencies are expected to require alteration as shown in Eqns. (16) and (17) based on the wing sweep angle.

$$
\begin{aligned}
& \beta_{s}=\beta_{0} \cos \left(\gamma_{s}+\alpha\right) \cos (\Lambda) \\
& \beta_{f b}=\beta_{0} \cos \left(\gamma_{f b}+\alpha\right) \cos (\Lambda)
\end{aligned}
$$

The experiments performed were constructed to determine if the modifications to the scaling approach for wing sweep in Eqns. (11), (16), and (17) are sufficient to capture surface roughness variations and temporal evolution on swept wings. If the temporal and spatial modifications capture the development of roughness on swept wings, then the results would indicate that the underlying physical mechanisms for roughness evolution on swept wings are the same as the roughness formation mechanisms on straight wings. 

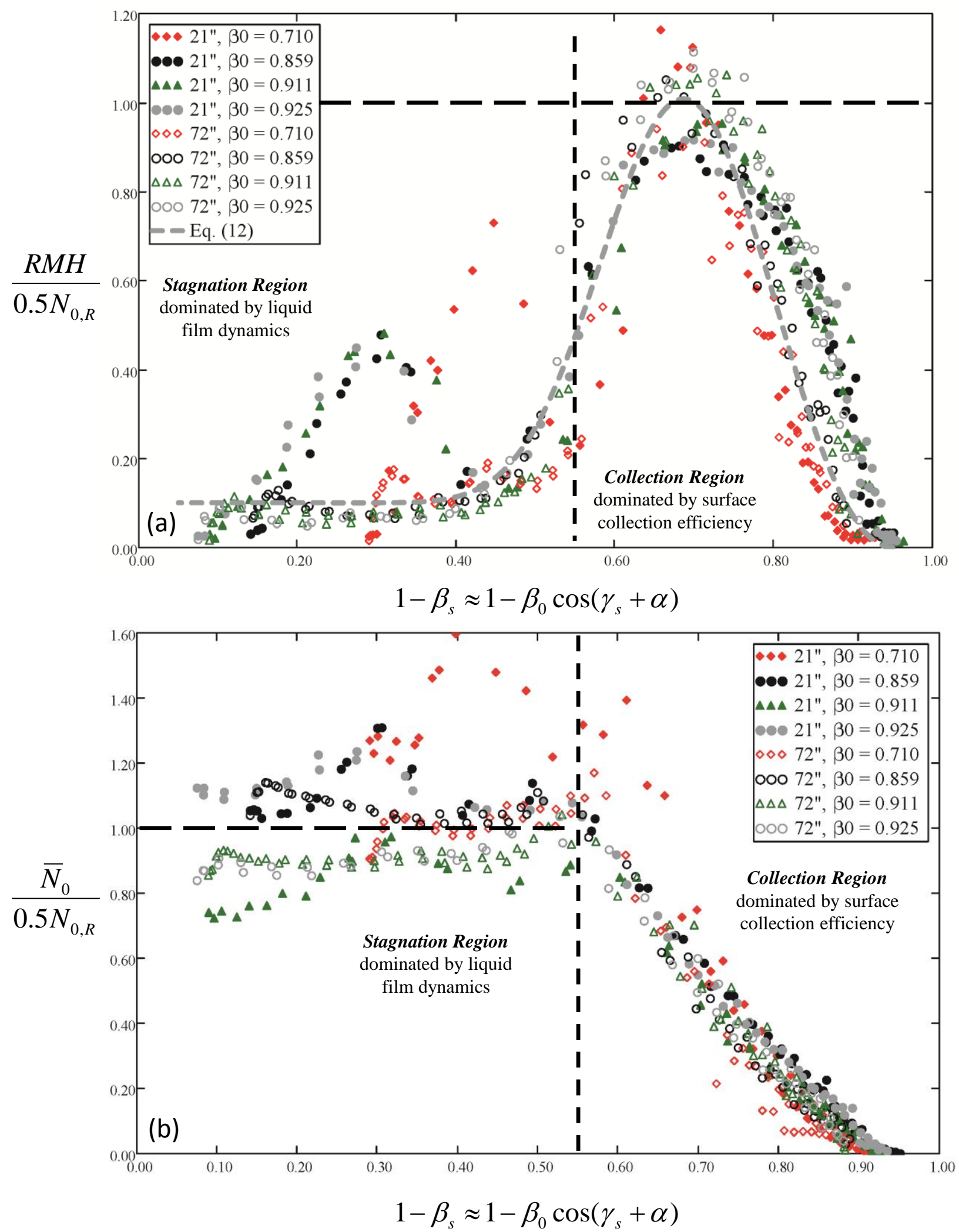

Figure 2. Scaled Roughness Height and Thickness Variations versus Local Collection Efficiency for Unswept Wings [10]: (a) Roughness and (b) Thickness

6

American Institute of Aeronautics and Astronautics 


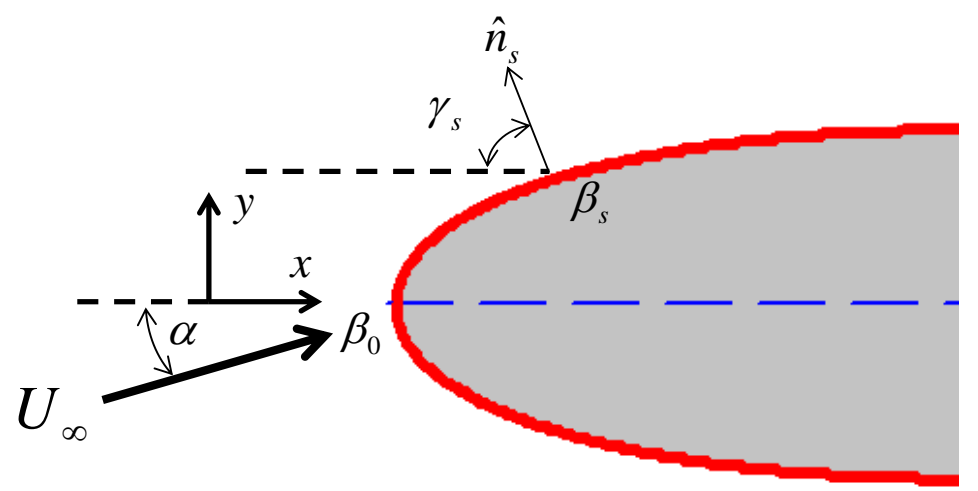
Figure 3. Unswept Airfoil Geometry Relating to the Local Surface Collection Efficiency $\left(\beta_{s}\right)$ Relative to the
Stagnation Point Collection Efficiency $\left(\beta_{0}\right)$

\section{Methodology}

To investigate ice roughness and thickness evolution on a swept airfoil and their similarities to roughness and thickness evolution on straight airfoils, the ice shapes were 1) created, 2) measured, and then 3) characterized using the SOM approach of McClain and Kreeger [17] for a wing swept at $30^{\circ}$. The following sections describe each of the ice roughness generation and characterization steps.

\section{A. Ice Shape Generation}

All of the experimental measurements were performed in the IRT over two nights of testing. A 91.44-cm (36in.) chord NACA 0012 airfoil, swept at $30^{\circ}$, was used for the study. The swept airfoil spanned 152.4-cm (60-in) long. One of the nights of testing was devoted to Appendix C conditions, and the other night was devoted to Appendix $\mathrm{O}$ or supercooled large droplet (SLD) icing conditions.

The flow conditions chosen for the Appendix $\mathrm{C}$ tests were essentially the same conditions employed by

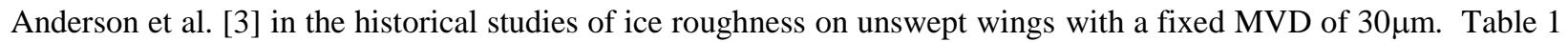
presents the freestream static and total temperatures, the freestream velocity, the median volumetric diameter, the liquid water content, the accumulation parameter, the freezing fraction, and the stagnation point collection efficiency. As shown in Table 1, the primary experimental dimensions varied during the tests as the ice accretion time resulting in accumulation parameters ranging from 0.03 to just under 0.5 .

Table 2 presents the cases for the SLD tests. All of the SLD tests were performed using an MVD of $150 \mu \mathrm{m}$. Comparing Tables 1 and 2, the static air temperatures and LWCs were kept consistent between all tests. However, the freestream velocity for the SLD cases was slightly lower than for the Appendix C cases. Combined with the larger droplet size, the slightly lower velocity, which is still within the IRT velocity controllability of $\pm 0.5 \mathrm{~m} / \mathrm{s}$ [18], resulted in lower stagnation point freezing fractions, $n$, for the SLD cases $(0.19$ versus 0.22 for the Appendix C cases).

For each test, the airspeed and freestream total temperature were set and the spray bar air and water pressures were selected to provide the appropriate LWC, MVD, and freezing fraction. A thermocouple embedded in the NACA 0012 airfoil was used to determine when the airfoil had reached thermal equilibrium with the flow. Once the thermocouple reported the static temperature of the flow indicating that it was in thermal equilibrium with the flow, the spray bars were actuated and closed after the predetermined spray time.

\section{B. Ice Shape Measurement}

Following the completion of the icing spray, the wind tunnel velocity was reduced to less than $10 \mathrm{knots}(5 \mathrm{~m} / \mathrm{s})$ while keeping the static temperature around $-4{ }^{\circ} \mathrm{C}$ to avoid thawing of the ice shape. The iced airfoil was painted using a tetrahydrofuran (THF)-based titanium dioxide paint. A ROMER Absolute Arm laser scanning system was placed in the IRT test section upstream of the airfoil. A scan was then made of the leading 200-250 mm of the airfoil leading edge (in the streamwise direction) on both sides of the airfoil downstream of the leading edge. The scans were approximately $150-\mathrm{mm}$ wide (in the spanwise direction) and were performed at the location of the airfoil corresponding to the center of the test section. 
Table 1. Summary of Test Parameters for the Appendix C Tests

\begin{tabular}{|c|c|c|c|c|c|c|c|c|c|c|}
\hline $\begin{array}{c}\text { Case } \\
\text { Number }\end{array}$ & $\begin{array}{l}\boldsymbol{T}_{\text {static }} \\
\left({ }^{\circ} \mathbf{C}\right)\end{array}$ & $\begin{array}{l}T_{\text {total }} \\
\left({ }^{\circ} \mathbf{C}\right)\end{array}$ & $\mathbf{V}(\mathbf{m} / \mathbf{s})$ & $\begin{array}{c}\text { MVD } \\
(\mu \mathrm{m})\end{array}$ & $\begin{array}{c}\mathbf{L W C} \\
\left(\mathrm{gm} / \mathrm{m}^{3}\right)\end{array}$ & $\begin{array}{c}\Delta t_{s} \\
(\mathrm{sec})\end{array}$ & $A_{c}$ & $n$ & $\beta_{0}$ & $\beta_{\Lambda}$ \\
\hline 012816.01 & -4.6 & -2.3 & 67.1 & 30.0 & 0.60 & 20 & 0.030 & 0.22 & 0.713 & 0.617 \\
\hline 012816.02 & -4.6 & -2.3 & 67.1 & 30.0 & 0.60 & 40 & 0.060 & 0.22 & 0.713 & 0.617 \\
\hline 012816.03 & -4.6 & -2.3 & 67.1 & 30.0 & 0.60 & 60 & 0.091 & 0.22 & 0.713 & 0.617 \\
\hline 012816.04 & -4.6 & -2.3 & 67.1 & 30.0 & 0.60 & 80 & 0.121 & 0.22 & 0.713 & 0.617 \\
\hline 012816.05 & -4.6 & -2.3 & 67.1 & 30.0 & 0.60 & 100 & 0.151 & 0.22 & 0.713 & 0.617 \\
\hline 012816.06 & -4.6 & -2.3 & 67.1 & 30.0 & 0.60 & 160 & 0.242 & 0.22 & 0.713 & 0.617 \\
\hline 012816.07 & -4.6 & -2.3 & 67.1 & 30.0 & 0.60 & 240 & 0.363 & 0.22 & 0.713 & 0.617 \\
\hline 012816.08 & -4.6 & -2.3 & 67.1 & 30.0 & 0.60 & 320 & 0.484 & 0.22 & 0.713 & 0.617 \\
\hline
\end{tabular}

Table 2. Summary of Test Parameters for the SLD Tests

\begin{tabular}{|c|c|c|c|c|c|c|c|c|c|c|}
\hline $\begin{array}{c}\text { Case } \\
\text { Number }\end{array}$ & $\begin{array}{c}\boldsymbol{T}_{\text {static }}\left({ }^{\circ} \mathbf{C}\right)\end{array}$ & $\begin{array}{c}\boldsymbol{T}_{\text {total }} \\
\left({ }^{\circ} \mathbf{C}\right)\end{array}$ & $\mathbf{V}(\mathbf{m} / \mathbf{s})$ & $\begin{array}{c}\mathbf{M V D} \\
(\boldsymbol{\mu m})\end{array}$ & $\begin{array}{c}\mathbf{L W C} \\
\left(\mathbf{g m} / \mathbf{m}^{\mathbf{3}}\right)\end{array}$ & $\begin{array}{c}\Delta \boldsymbol{\Delta t}_{\boldsymbol{s}} \\
(\mathbf{s e c})\end{array}$ & $\boldsymbol{A}_{\boldsymbol{c}}$ & $\boldsymbol{n}$ & $\boldsymbol{\beta}_{0}$ & $\boldsymbol{\beta}_{\boldsymbol{A}}$ \\
\hline 012916.01 & -4.6 & -2.4 & 66.7 & 150.0 & 0.60 & 20 & 0.030 & 0.19 & 0.953 & 0.825 \\
\hline 012916.02 & -4.6 & -2.4 & 66.7 & 150.0 & 0.60 & 40 & 0.060 & 0.19 & 0.953 & 0.825 \\
\hline 012916.03 & -4.6 & -2.4 & 66.7 & 150.0 & 0.60 & 60 & 0.090 & 0.19 & 0.953 & 0.825 \\
\hline 012916.04 & -4.6 & -2.4 & 66.7 & 150.0 & 0.60 & 80 & 0.120 & 0.19 & 0.953 & 0.825 \\
\hline 012916.05 & -4.6 & -2.4 & 66.7 & 150.0 & 0.60 & 100 & 0.150 & 0.19 & 0.953 & 0.825 \\
\hline 012916.06 & -4.6 & -2.4 & 66.7 & 150.0 & 0.60 & 160 & 0.241 & 0.19 & 0.953 & 0.825 \\
\hline 012916.07 & -4.6 & -2.4 & 66.7 & 150.0 & 0.60 & 240 & 0.361 & 0.19 & 0.953 & 0.825 \\
\hline 012916.08 & -4.6 & -2.4 & 66.7 & 150.0 & 0.60 & 320 & 0.481 & 0.19 & 0.953 & 0.825 \\
\hline
\end{tabular}

\section{SOM Roughness and Thickness Evaluation}

The surface point clouds were then processed using the Self-Organizing Map (SOM) approach developed by McClain and Kreeger [17]. The self-organizing map, or sometimes referred to as a Kohonen Map, is a clustering method for the detection of non-linear manifolds, which may be curves or surfaces, in multi-dimensional space [19]. SOMs depend on the use of codebook vectors, $\mathbf{b}$, which may also be called codebook points or neurons, to represent clumps of data. Following convergence of the SOM method, each codebook vector will be located at the spatial centroid of the clump of data that it represents. In its simplest essence, self-organizing maps are employed to capture trends of large data sets by representing those large data sets by a relatively small set of codebook vectors. When applied to an ice shape, the intent of performing the SOM is to extract the "form" of the ice shape from the surface variations. For detailed information on self-organizing maps and their application for iced airfoil description and roughness evaluation, please consult Refs. [17] and [20].

When applied to an iced airfoil point cloud without sweep or significant spanwise shape changes, the SOM is expected to identify a curve in the Chord-Chord Normal plane (or x-y plane when the spanwise axis is placed in the z-direction), which represents the mean shape of the rough airfoil. The nature of the SOM method and the positioning of the codebook vectors along a "daisy-chain" enable a statistical evaluation of iced airfoil surface roughness. Since the "clumps" of points are distributed about the codebook vectors, the deviations of the point measurements in the clumps can be used to evaluate the coverage statistics and uncertainty of the codebook vector representation.

Figure 4 shows a single surface measurement, $\mathbf{x}^{\mathbf{j}}$, and its closest codebook vector $\mathbf{b}^{\mathbf{n}}$. The two neighboring codebook vectors along the daisy-chain of codebook vectors representing the manifold are also shown. In the approach used for this study, the manifold is assumed to be a first-order manifold in two-dimensional space with the characteristic that at each codebook vector the local slope of the manifold is equal to the central finite-difference evaluated using the two closest surrounding codebook vectors. The approach used assumes that all deviations from the manifold are normal to the manifold. That is, the deviation of a surface measurement normal to the line through the codebook vector with the local slope set by the neighboring codebook vectors is considered the "height" of the surface point above or below the local manifold. 


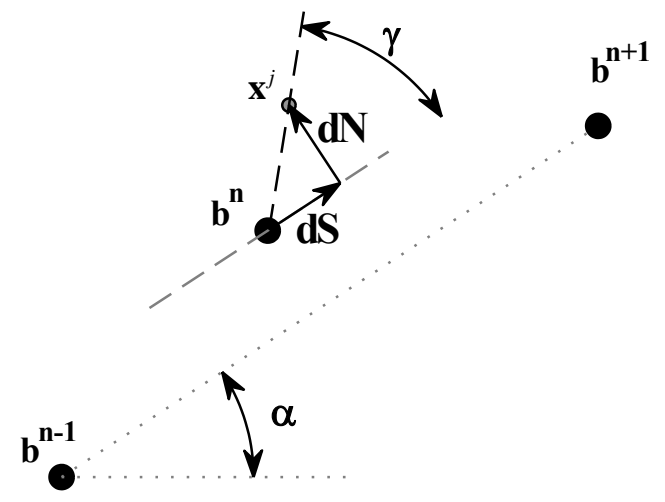

Figure 4. Metrics of Local Point about a Codebook Vector [9]

Based on the SOM-manifold description, the root-mean-square roughness height is calculated at each codebook vector as

$$
R_{q}=\left[\frac{1}{J} \sum_{j=1}^{J} N_{\mathbf{x}^{j}}\right]^{\frac{1}{2}}
$$

In some roughness studies, the $99.9 \%$ roughness maximum height (RMH) based on a Gaussian distribution is calculated using 3.09 times the root-mean-square roughness height.

$$
R M H_{\mathbf{b}^{\mathbf{n}}}=3.09 R_{q}=3.09\left[\frac{1}{J} \sum_{j=1}^{J} N_{\mathbf{x}^{j}}{ }^{2}\right]^{\frac{1}{2}}
$$

Where $J$ is the number of surface points for which $\mathbf{b}^{\mathbf{n}}$ is the winning (closest) codebook vector. The RMH is the local 99.9\%-maximum roughness height and is evaluated at each codebook vector based on the local or neighborhood statistics. The RMH will vary along the surface arc length. While the RMH is not a universal roughness descriptor, the RMH value is important for this study. Since the RMH represents a Gaussian prediction of the $99.9 \%$ maximum distance from the mean elevation to the tallest peaks in a data set, the RMH is a reasonable tool to compare the statistical results to the morphological descriptors such as roughness element diameter and height used in the historical roughness studies. More details regarding the roughness evaluation and the associated measurement uncertainties may be found in McClain [19].

The ice thickness relative to the clean airfoil shape, $N_{0 x}{ }^{j}$, is calculated in a fashion very similar to the ice roughness height, as demonstrated in Figure 4, with the exception of instead of using the codebook vector as the surface reference, the original airfoil design coordinates are used. Further details regarding the ice thickness evaluation may be found in McClain [19].

The point clouds were analyzed using the Airfoil Roughness Evaluation System (ARES), which was developed to automate the roughness characterization approach of McClain and Kreeger [17]. The approach of McClain and Kreeger [17] was originally implemented using multiple software tools. ARES is a set of Matlab functions that performs the SOM characterization of the mean ice shape and then performs the two-dimensional statistical analyses required to characterize the roughness variations along the airfoil surface in the flow direction. After being read into ARES, the point clouds were rotated to be aligned with the primary axis of the wing. Consequently, the roughness and thickness measurements are performed in the projected $X-Y$ airfoil coordinate system (as opposed to the wind tunnel coordinate system) and result in "surface orthogonal" roughness and thickness measurements. 


\section{Results and Discussion}

The results of the investigation are divided into three separate aspects: 1) visualization of roughness and thickness topographical variations, 2) temporal roughness and thickness evolution, and 3) spatial roughness variations and scaling. Each aspect of the results is described in the following subsections.

\section{A. Visualization of Roughness and Thickness Topography}

Figure 5 presents a visual comparison of the roughness and thickness topographies for the 012816.05 case compared to the 012916.05 case. Both cases have the same icing event times, $\Delta t_{s}$, of 100 seconds. However, the 012816.05 case is an Appendix C case $($ MVD $=30 \mu \mathrm{m})$, and the 012916.05 case is an SLD case (MVD $=150 \mu \mathrm{m})$. The top row, Figures 5(a) and 5(b), are the roughness and thickness for the 012816.05 case, and the bottom row, Figures 5(c) and 5(d), are the roughness and thickness for the 012916.05 case.

Figure 5 demonstrates that while the icing event times are the same, the roughness and thickness topographies are very different. The magnitudes of the maximum roughness height and the maximum ice thicknesses are not noticeably different. However, because of the difference in stagnation point collection efficiency, caused by the larger droplet size, the ice roughness and thickness extends much further along the airfoil surface in the flow direction for the SLD case.

Figures 6 and 7 present the spanwise average ice roughness and thickness measurements measured at each codebook vector of the SOM representation as a function of surface distance along the airfoils. Figure 6(a) presents the RMH variations for the Appendix C cases, while Figure 6(b) presents the RMH variations for the SLD cases. In addition to demonstrating the increasing roughness values as functions of time at any location, Figure 6 reinforces observations from Figure 5 regarding the ice thickness and roughness regions. That is, while the magnitudes of the maximum RMH values for any one case are similar, the roughness variations along the surface are very different between the Appendix C and SLD cases. Most importantly, the length of the glaze-ice plateau in the flow direction, as demonstrated in Figure 7, is significantly larger for the SLD cases than for the Appendix C cases. This extended plateau region suggest a longer liquid film region before film breakdown leading to the maximum roughness values of Figure 6 occurring further aft for the SLD cases than for the Appendix C cases.

Figure 7(a) presents the average ice thickness values evaluated at each SOM codebook vector for the Appendix C cases, while Figure 7(b) presents the average ice thickness values for the SLD cases. Just as was the case for the roughness values, the maximum ice thickness values are not significantly different, but the distributions of ice along the surface of the Appendix C cases is much different than the distributions along the surface for the SLD cases. While the distributions are different, the most significant difference is that the nearly flat region near the attachment line (since the wing is swept) of the wing, which represents the glaze-ice plateau, is significantly wider for the SLD cases than for the Appendix C cases.

\section{B. Scaled Roughness and Thickness Temporal Variations}

Figures 8 and 9 present the airfoil maximum roughness (AMR) and attachment line thickness $\left(\bar{N}_{0, A L}\right)$ evolutions in dimensionless form. Since the wings used in the study have a symmetric airfoil shape, the AMR values are defined as the average of the maximum RMH value on the left side of the wing in Figure 6 and the maximum RMH on the right side of the airfoil.

$$
A M R=\frac{R M H_{\max , R i g h t}+R M H_{\max , \text { Left }}}{2}
$$

In Figures 8 and 9, the AMR values and stagnation point thickness measurements are nondimensionalized by $2 r_{0}$, while the ice accretion times, which are expressed as attachment-line fully-dense rime ice thicknesses, are nondimensionalized by $2 r_{0}$ as well. The dashed line shown in Figures 8 and 9 represent a $C_{t}$ value of 0.5 in Eqns. (10) and (12) as found from the unswept-wing roughness evolution investigations. Figures 8 and 9 demonstrate that the scaled AMR values as well as the scaled attachment-line thickness values for swept wings are increasing at rates nearly identical to the rates found on straight wings. 

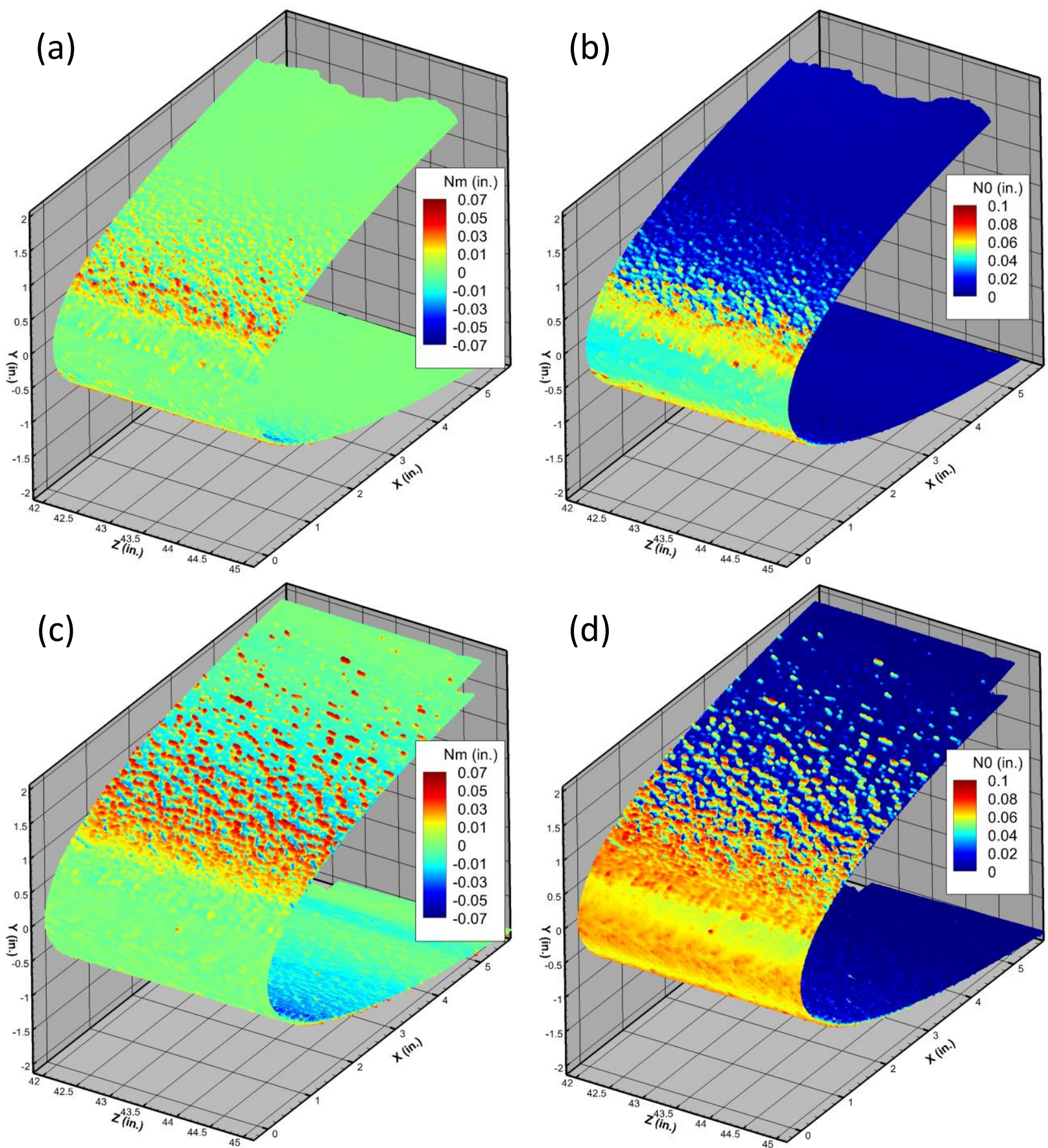

Figure 5. Surface Visualizations of the 100-second Cases: (a) IRT012816.05 Roughness Topography, (b) IRT012816.05 Thickness Topography, (c) IRT012916.05 Roughness Topography, (d) IRT012916.05 Thickness Topography (Top row: Appendix C, Bottom Row: SLD) 

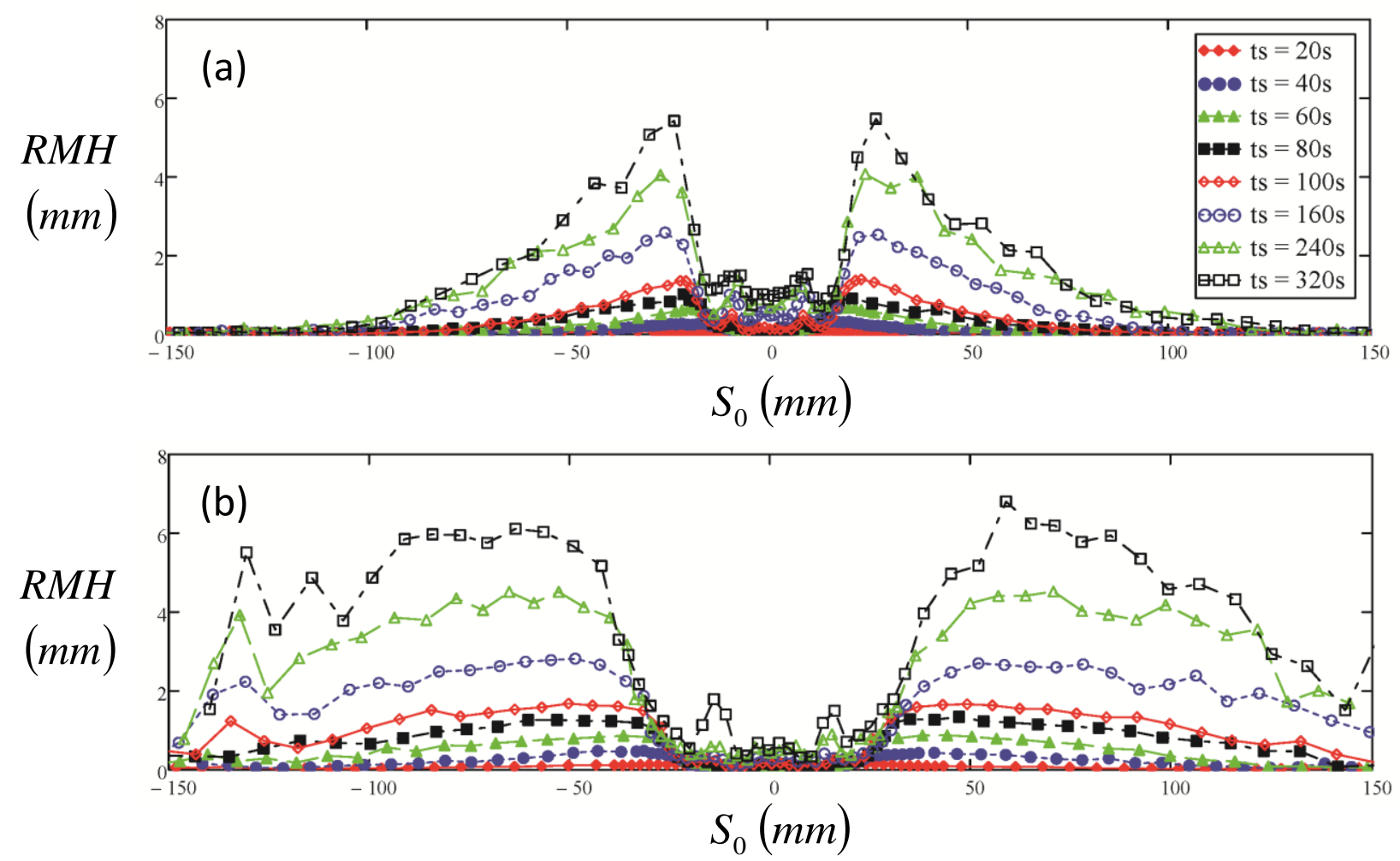

Figure 6. Surface Roughness Profiles along the NACA 0012 Surface Direction: (a) the Appendix C Cases and (b) the SLD Cases
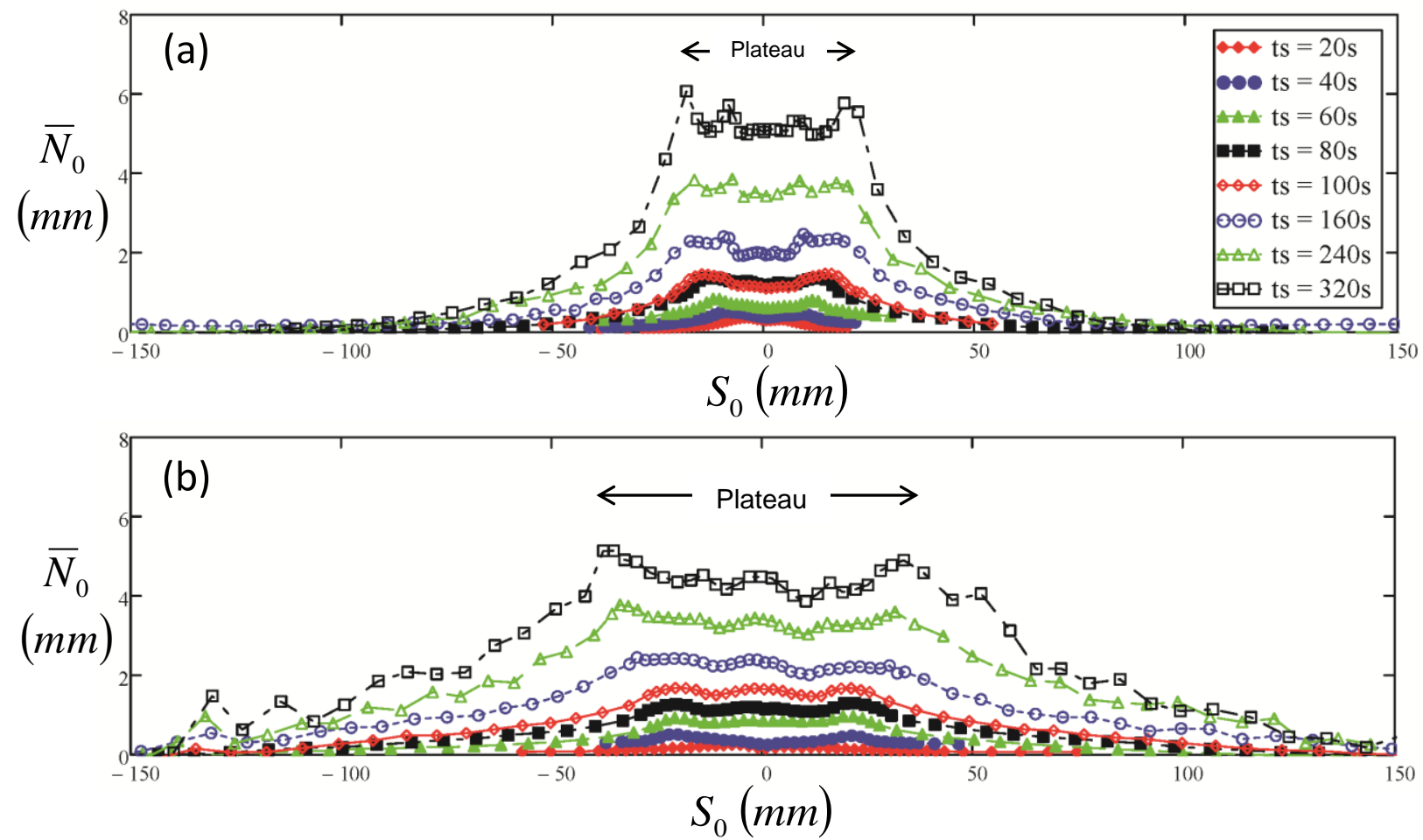

Figure 7. Appendix C Thickness Profiles along the NACA 0012 Surface Direction: (a) the Appendix C Cases and (b) the SLD Cases

12

American Institute of Aeronautics and Astronautics 


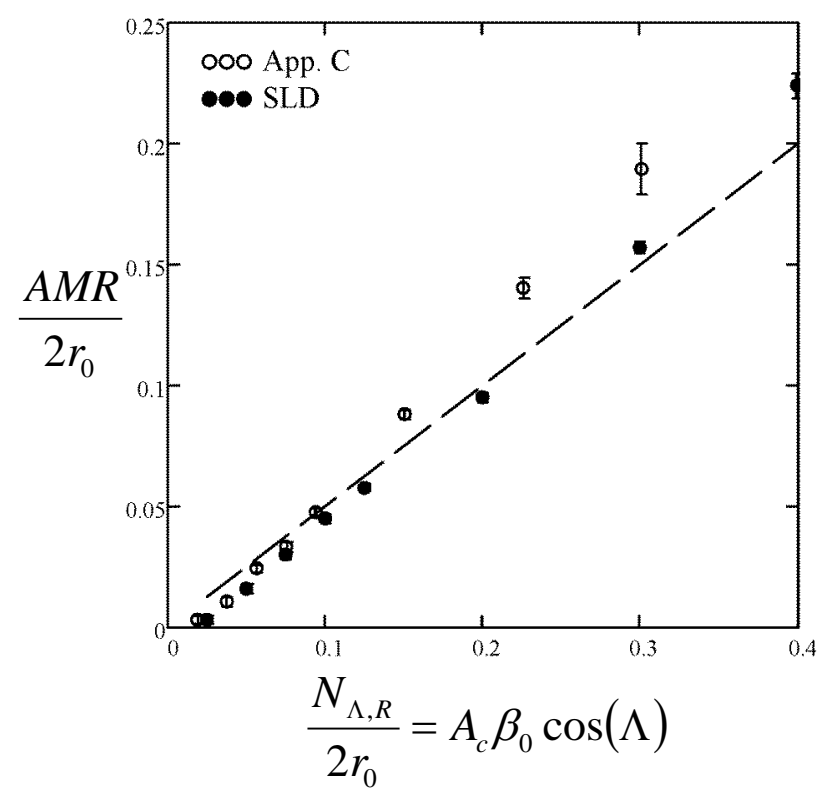

Figure 8. Dimensionless Maximum Roughness Temporal Variation

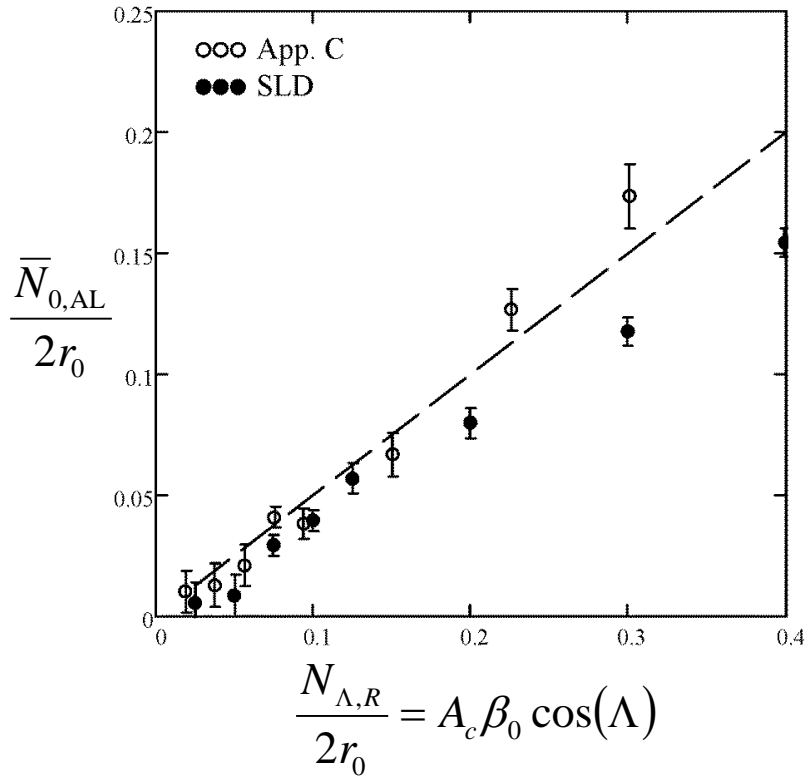

Figure 9. Dimensionless Stagnation Point Thickness Temporal Variation

Investigating Figure 8 closely, for relative theoretical Rime ice thicknesses $\left(N_{\Lambda, R} / 2 r_{0}\right)$ less than 0.1 , the relative airfoil maximum roughness heights $\left(A M R / 2 r_{0}\right)$ are lower than the $C_{t}=0.5$ line. Figure 10 presents the airfoil maximum relative roughness values relative to the theoretical Rime ice thickness (AMR/ $N_{\Lambda, R}$ ) versus the relative Rime ice thickness growth values. Figure 10 demonstrates that both the Appendix C and SLD cases exhibit an asymptotic behavior approaching a $C_{t}$ value around 0.6. The asymptotic behavior is reminiscent of a "first-order differential equation" effect, which would suggest an alteration to the temporal function of Eq. (10) to include a decaying exponential function as indicated in Eq. (20).

$$
\mathcal{J}(\tau)=C_{t}\left(1-e^{-t / t_{0}}\right) N_{0, R}
$$

where $t_{0}$ would be a time constant based on the cloud properties, flow characteristics, or possibly the liquid film dynamics.

However, Figure 11 presents the relative maximum roughness values (AMR/ $\left.N_{\Lambda, R}\right)$ versus $A_{c} \cos (\Lambda)$, which is essentially the same abscissa as the relative, theoretical Rime ice thickness in Figure 10 without the influence of the cloud properties associated with the stagnation point collection efficiency, $\beta_{0}$. Figure 11 demonstrates that the Appendix C and SLD asymptotic response collapse similarly to Figure 10.

The fact that the data collapse similarly between Figure 10 with $\beta_{0}$ and Figure 11 without $\beta_{0}$ suggests that factors other than the stagnation collection efficiency of the cloud may be introducing a first-order transient response. That is, since the base cloud properties in the accumulation parameters are the same for all of the cases in this study resulting in an abscissa which is simply a scaled time function, the asymptotic behavior captured in Figures 10 and 11 could be a product of wing internal conduction, conduction through the ice layer growing on the wing, or a real phenomenon associated with the roughness evolution physics.

The transient artifact noted in Figures 10 and 11 may also be exhibited by the prior data for roughness evolution on straight wings. However, the ice accretion time progression measurements of McClain et al. [8] and McClain et al. [9] for straight 21-in. chord NACA 0012 airfoils have not been processed using the scaling factors employed in Figures 10 and 11. Understanding the true source of the first-order behavior, may require revising the straight-wing measurements; acquiring more measurements in the IRT for different cloud properties, specifically, different liquid water contents, freestream velocities; and acquiring roughness evolution measurements on airfoils and wings with a different construction from the solid aluminum wings employed in this study. 


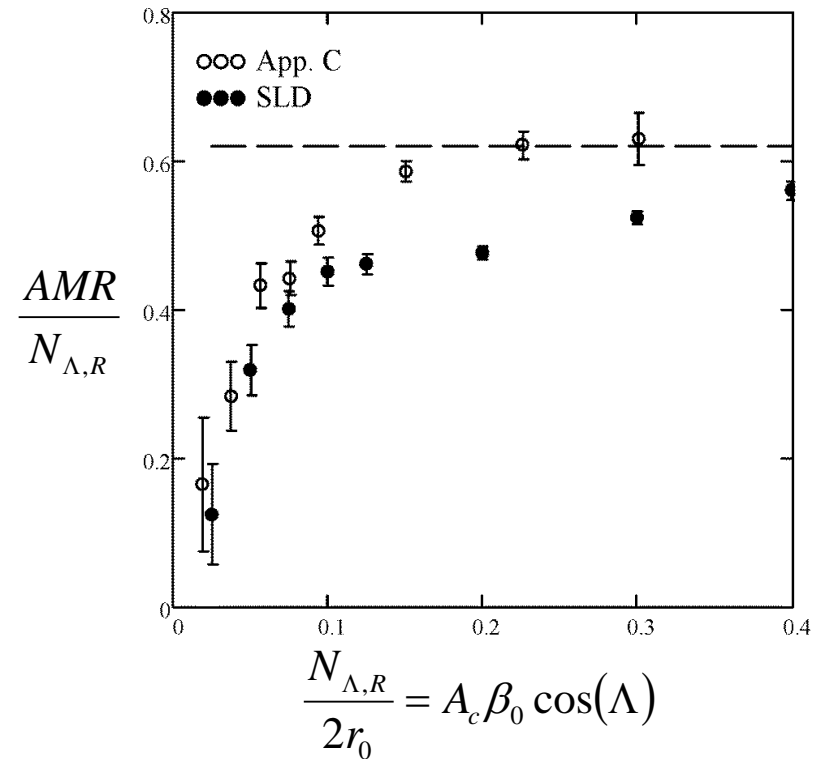

Figure 10. Relative Maximum Roughness Temporal Variation

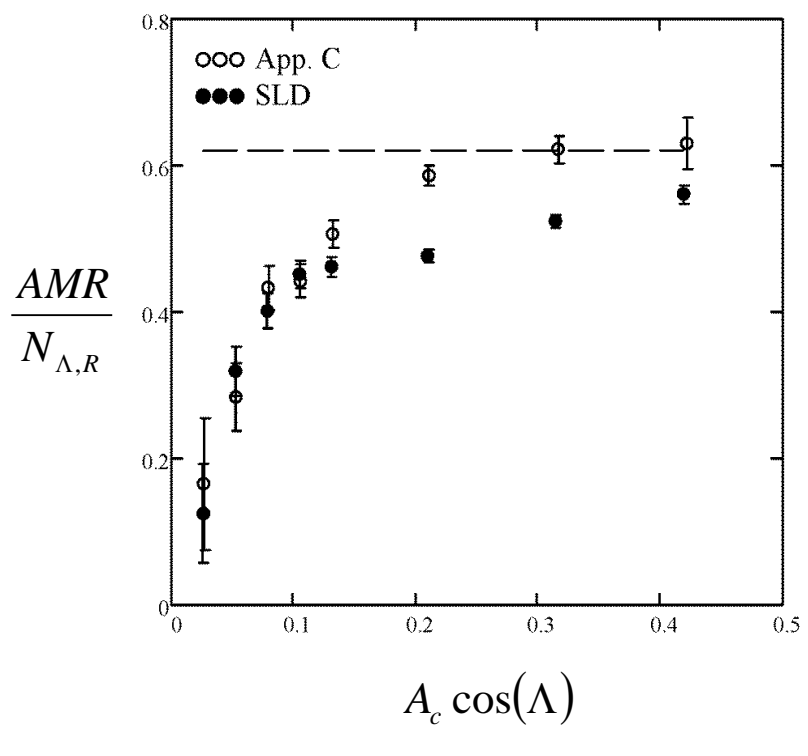

Figure 11. Alternate Relative Roughness Temporal Variation

\section{Surface Roughness Spatial Variation}

Figure 12 presents the roughness height variations of Figure 6 scaled by one-half the theoretical Rime ice thickness and plotted versus the local collection efficiency as defined in Eq. (16) for swept wing surfaces as was done similarly for Figure 2 for roughness on straight wings. In Figure 12, Figure 12(a) presents the Appendix C conditions, and Figure 12(b) presents the SLD conditions. Both Figures 12(a) and 12(b) indicate surface roughness distributions similar to those reported by McClain et al. [10] for straight wings. That is, both the Appendix C and SLD surface distributions exhibit regions near the glaze ice plateau with low values of roughness height (RMH/ $N_{\Lambda, R}$ $\approx 0.1$ ). Downstream of local surface collection efficiencies around 0.5 , the RMH values rapidly increase to a maximum and then decay as the surface angles get closer and closer to $90^{\circ}$ to the freestream.

Also evident in Figure 12(a) and 12(b) is the first-order transient or asymptotic behavior noted in Figures (10) and (11). That is, at accretion event times less than 160 seconds, the measured roughness profiles are similar, but the magnitudes are increasing as the accretion time increases. After accretion times of 160 seconds, the measured roughness profiles exhibit essentially the same magnitudes.

The gray dashed lines in Figure 12(a) and Figure 12(b) are the straight wing surface roughness variation trend presented in Eq. (12) using a liquid film breakdown collection efficiency $\left(\beta_{f b}\right)$ of 0.45 , which was the same film breakdown collection efficiency used for the unswept NACA 0012 cases of Figure 2, and a $C_{t}$ value of 0.5. Figure 12(a) demonstrates that once the asymptotic conditions are approached, the swept wing Appendix $\mathrm{C}$ roughness distributions exhibit RMH values slightly above the straight wing curve. However, the surface distributions of the asymptotic Appendix $\mathrm{C}$ cases are captured by the straight wing distribution function.

The asymptotic SLD results presented in Figure 12(b) do not collapse as well onto the unswept wing surface variation trend of Eq. (12) as well as the asymptotic Appendix C cases. As shown in Figure 12(b), the magnitudes of the RMH maximums is close to the unswept-wing maximum, but the SLD surface distributions appear wider, indicating a larger Weibull modulus or shape factor, and appear to be shifted downstream along the surface. This shift of the surface roughness profiles may be expected for cases with a much lower freezing fraction. While the SLD cases did have a slightly lower freezing fraction of 0.19 compared to 0.22 for the Appendix C cases, the difference was not expected to affect the surface roughness profiles as much as exhibited in Figure 12(b). 

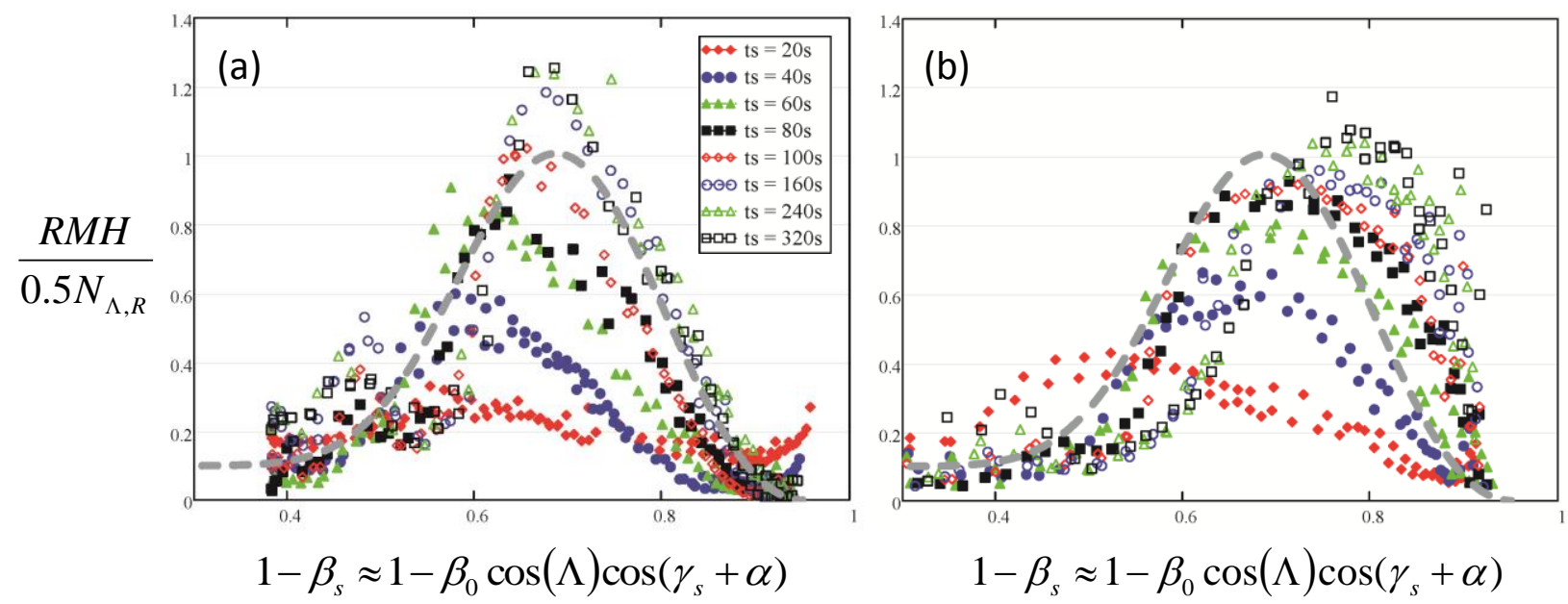

Figure 12. Airfoil Dimensionless Roughness Variations along Surface Related to the Local Collection Efficiency

\section{Final Observations Relative to Unswept Wing Roughness}

While the swept-wing SLD surface roughness distributions are slightly shifted from the unswept-wing surface roughness distribution and the Appendix $\mathrm{C}$ swept-wing roughness distributions, the swept wing ice thickness and roughness temporal evolution results of Figures 8 and 9 are almost identical to the temporal evolution of ice thickness and roughness on unswept wings. The asymptotic behaviors of the swept wing surface roughness distributions also exhibit the liquid-film dominated regions near the leading edge and the collection efficiency dominated regions near the impinging limits exhibited in the unswept wing results. Further, the asymptotic, sweptwing Appendix $\mathrm{C}$ cases exhibited nearly identical locations of liquid-film breakdown as was identified in the unswept-wing cases. While the sources of the first-order transient effects noted and the shift in the swept-wing SLD surface roughness profiles require further investigation, the results suggest that asymptotic swept wing and unswept wing ice roughness temporal and spatial variations may be modeled using:

$$
R M H\left(N_{\Lambda, R}, \beta_{s}, \beta_{f b}\right)=C_{t} N_{\Lambda, R}\left[\frac{W e i\left(\beta_{s}-0.05, \beta_{f b}-0.15,3\right)}{W e i\left(0.875\left(\beta_{f b}-0.15\right), \beta_{f b}-0.15,3\right)}+\left(\frac{0.1}{2}-\frac{0.1}{2} \tanh \left[10\left(\beta_{f b}-\beta_{s}\right)\right]\right)\right]
$$

where

$$
\begin{gathered}
N_{\Lambda, R}=2 r_{0} A_{c} \beta_{0} \cos (\Lambda) \\
\beta_{s}=\beta_{0} \cos \left(\gamma_{s}+\alpha\right) \cos (\Lambda) \\
\beta_{f b}=\beta_{0} \cos \left(\gamma_{f b}+\alpha\right) \cos (\Lambda)
\end{gathered}
$$

When the sweep angle, $\Lambda$, is $0^{\circ}$, Eqns. (21)-(24) reduce to the expressions provided in the Introduction section for unswept wings.

An additional limitation on Eq. (21) relates to the effects of the stagnation point freezing fraction, $n$. The range of freezing fractions employed in this study and in the prior laser-scan ice roughness investigations is 0.19-0.25. Different freezing fractions are expected to affect the roughness surface distribution in three ways: 1) different freezing fractions may lead to different $C_{t}$ values, 2) different freezing fractions are expected to change the location of the liquid-film breakdown $\left(\beta_{f b}\right)$, and 3) different freezing fractions may increase the width of the roughness distribution which could be accounted for by different values of Weibull modulus. Future efforts are required to determine the importance of and modifications required to account for the effects of different stagnation point freezing fractions on the surface roughness spatial distributions. 


\section{Conclusions}

As part of an extended study on the physics of ice roughness evolution and ice roughness surface distributions, the characteristics of ice roughness on swept wings were investigated using ice accretion time progressions for Appendix C and SLD conditions. Both Appendix C and SLD conditions were investigated using a 36-in. NACA 0012 wings with $30^{\circ}$-sweep. The time and collection efficiency based scaling system presented by McClain et al. [10] for unswept wings was modified to consider wing sweep. Using the scaling modifications for sweep, the temporal and spatial roughness variations on the swept wing were compared to the previous roughness investigations for straight wings. The primary findings are:

1) The temporal variations in maximum roughness height and attachment line ice thickness followed the straight wing results when the sweep-modified scaling parameters were employed.

2) The temporal variations exhibited a first-order-differential-equation based asymptotic or capacitance-like behavior in time. While the effect may be a real phenomenon associated with the roughness formation process, airfoil internal conduction or ice layer internal conduction cannot be eliminated as contributing to the transient behavior observed. The prior unswept wing measurements from McClain et al. [8] and McClain et al. [9] must be revisited, and more tests may be required to determine the source of the asymptotic behavior in the scaled roughness results.

3) Once the asymptotic time value was reached, the spatial variations exhibited on swept wings in Appendix C conditions were consistent with the spatial variations on straight wings.

4) Once the asymptotic time value was reached, the spatial variations exhibited in SLD conditions were similar to the behavior found on straight wings, but the location of the glaze plateau was shifted further downstream and the roughness distribution along the airfoil surface was wider than exhibited on straight wings. The source of the spatial differences for the swept-wing SLD cases is not well understood.

The results of the investigation suggest that the basic physics of roughness formation and evolution on swept wings are the same as those on straight wings and involve the competing phenomena associated with liquid-film region near the stagnation point or attachment line and the local collection efficiency downstream of the location of liquid-film breakdown. This observation is important because of the influence of the roughness elements on the formation of larger three-dimensional ice features formed on swept wings such as scallops. While the eventual large three-dimensional features on swept wings are very different from the primarily two-dimensional features on unswept wings following long ice accretion event times, both types of features begin as roughness that is evolving similarly and from the same mechanisms on straight and swept wings.

\section{Acknowledgments}

The efforts reported in this paper were partially supported as part of NASA Collaborative Agreement No. NNX12AB85A. The authors thank Mr. Richard E. Kreeger, Mr. Quentin Schwinn, Ms. Jordan Salkin, Dr. Sam Lee and Dr. Andy Broeren for their assistance with the study. Finally, the authors thank Peter Tino of the University of Birmingham, UK whose class notes inspired the initial SOM investigation of ice shapes and who provided many suggestions for improving the roughness characterization approach in the early stages if its development. Any opinions presented in this paper are those of the authors and do not reflect the views of NASA or the United States government.

\section{References}

${ }^{1}$ Shin, J.,(1994), "Characteristics of Surface Roughness Associated With Leading Edge Ice Accretion,” NASA TM-106459.

${ }^{2}$ Anderson, D. N., and Shin, J., (1997), “Characterization of Ice Roughness from Simulated Icing Encounters,” NASA TM107400

${ }^{3}$ Anderson, D. N., Hentschel, D. B., and Ruff, G. A., (1998), "Measurement and Correlation of Ice Accretion Roughness," NASA CR-2003-211823

${ }^{4}$ Lee, S., Broeren, A., Addy, H., Sills, R., and Pifer, E., (2012), "Development of 3D Ice Accretion Measurement Method," AIAA-2012-2938, presented at the $4^{\text {th }}$ AIAA Atmospheric and Space Environments Conference, June 25-28.

${ }^{5}$ Lee, S., Broeren, A. P., Kreeger, R. E., Potapczuk, M., and Utt, L., (2014), "Implementation and Validation of 3-D Ice Accretion Measurement Methodology," 6th AIAA Atmospheric and Space Environments Conference, June 16-20, Atlanta, GA, AIAA-2014-2613. 
${ }^{6}$ Broeren, A. P., Addy, H. E., Lee, S., and Monastero, M. C., (2014), "Validation of 3-D Ice Accretion Masurement Methodology for Experimental Aerodynamic Simulation, 6th AIAA Atmospheric and Space Environments Conference, June 1620, Atlanta, GA, AIAA-2014-2614.

${ }^{7}$ Kreeger, R. E. and Tsao, J.-C., (2014), "Ice Shapes on a Tail Rotor," 6th AIAA Atmospheric and Space Environments Conference, June 16-20, Atlanta, GA, AIAA-2014-2612.

${ }^{8}$ McClain, S.T., Reed, D., Vargas, M., Kreeger, R.E., and Tsao, J.-C.,, (2014), "Ice roughness in Short Duration SLD Icing Events," Presented at the 6th AIAA Atmospheric and Space Environments Conference, June 16-20, Atlanta, GA, AIAA-20142330.

${ }^{9}$ McClain, S.T., Vargas, M., Kreeger, R.E., and Tsao, J.-C., (2015), “A Reevaluation of Appendix C Ice Roughness Using Laser Scanning," SAE 2015 International Conference on Icing of Aircraft, Engines, and Structures, June 22-25, Prague, Czech Republic, SAE2015-01-2098.

${ }^{10}$ McClain, S.T., Vargas, M., and Tsao, J.-C., (2016), "Characterization of Ice Roughness Variations in Scaled Glaze Icing Conditions," 8th AIAA Atmospheric and Space Environments Conference, June 13-17, Washington, DC, AIAA-2016-3592.

${ }^{11}$ Vargas, M., (2007), "Current Experimental Basis for Modeling Ice Accretions on Swept Wings," Journal of Aircraft, Vol. 44, No. 1, pp. 274-290.

${ }^{12} 14$ CFR, Aeronautics and Space, Part 25 Airworthiness Standards: Transport Category Airplanes, Section C25.1: Appendix C;" published by the Office of the Federal Register, National Archives and Records Administration, Washington, DC., Amdt. 25140, effective 5-Jan-2015.

13“"14 CFR Parts 25 and 33: Airplane and Engine Certification Requirements in Supercooled Large Drop, Mixed Phase, and Ice Crystal Icing Conditions," (2010), Federal Register, Vol. 75, No. 124, June 29, 37311-37339.

${ }^{14}$ Tsao, J.C. and Lee, S., "Evaluation of Icing Scaling on Swept NACA 0012 Airfoil Models," NASA/CR-2012-217419, May 2012.

${ }^{15}$ Tsao, J.C. and Kreeger, R.E., "Experimental Evaluation of Stagnation Point Collection Efficiency of the NACA 0012 Swept Wing Tip," AIAA-2009-4125 and NASA/TM-2010-216102, March 2010.

${ }^{16}$ Langmuir, I. and Blodgett, K. B. "A Mathematical Investigation of Water Droplet Trajectories," Army Air Forces Technical Report No. 5418, February 1946.

${ }^{17}$ McClain, S. T. and Kreeger, R. E., (2013), “Assessment of Ice Shape Roughness Using a Self-Organizing Map Approach,” Presented at the 5th AIAA Atmospheric and Space Environments Conference, June 24-27, San Diego, CA, AIAA-2013-2546.

${ }^{18}$ Steen, L.E., Ide, R.F, Van Zante, J.F., and Acosta, W.J., (2015), "NASA Glenn Icing Research Tunnel: 2014 and 2015 Cloud Calibration Procedure and Results," NASA/TM-2015-218758.

${ }^{19}$ Kohonen, T., (2001), Self-Organizing Maps, Berlin: Springer-Verlag, 3rd ed.

${ }^{20}$ McClain, S.T., (2016), "Manual Point Cloud Registration for Combined Ice Roughness and Ice Thickness Measurements," 8th AIAA Atmospheric and Space Environments Conference, June 13-17, Washington, DC, AIAA-2016-3590. 